In washed sections of viscera measles antigens were detected by immunofluorescence in isolated cells in the peripheral sinuses and within germinal centres in the cervical (Fig. 3), axillary, and mediastinal lymph nodes. It was not found in the abdominal lymph nodes. Measles antigens were also found in small groups of cells in the splenic pulp and in sparse cells in the walls of the sinuses in the liver. No specific fluorescence was seen in cells in the lungs, stomach, or small or large intestines.

Granular deposits of measles antigens were seen in capillaries and mesangial cells in 5\% of the renal glomeruli (Fig. 4). This antigen, too, could not be removed completely by elution with acid citrate or potassium thiocyanate but the intensity of the fluorescence was diminished by treatment with these reagents.

\section{Discussion}

These findings suggest that in subacute sclerosing panencephalitis immune complexes of measles antigen and IgG are present in the circulation. They should be confirmed during life by the many other immunological and virological techniques available. The occurrence of antigenic components and even of the pathogenetic measles-like virus itself has recently been shown in lymph nodes by Fuccillo et al. (1971) and HortaBarbosa et al. (1971).

The formation of immune complexes in diverse viral infections has recently been reviewed by Oldstone and Dixon (1971) and by Notkins (1971). Even though formal study of this problem has only just begun it is striking how many chronic or temperate viral infections are associated with the appearance of immune complexes. Circulating antibody complexes may contain infectious virus (Notkins, 1971), and it is possible that this is one means by which certain viruses survive as they spread from cell to cell, as well as being enabled to reach immunologically-protected sites or to achieve the local conditions required to initiate chronic infections. Complexes deposited in tissues can produce local damage by a variety of means (Cochrane, 1971; Henson, 1971), and these processes must be considered directly in analysing the pathological effects of temperate encephalitides (Webb, 1968).

The occurrence of the measles-like virus in the reticuloendothelial system in subacute sclerosing panencephalitis is intriguing and its significance is not clear. Burnet (1968) suggested that the disease was due to an abnormal lack of reactivity of thymus-derived immunocytes against measlesinfected cells and predicted that the thymus in these patients would contain measles antigen. Unfortunately, this could not be tested because of the lack of frozen thymic tissue. The distri- bution of measles antigen observed in the present case might represent phagocytosis of immune complexes, but it seems more likely to result from a degree of immunological tolerance which had permitted widespread dissemination of the aetiological agent.

Not all strains of animals infected with potentially "temperate" viruses actually develop chronic infections (Oldstone and Dixon, 1969). The occurrence of chronicity may be due to differences in the affinity of the antibodies produced (Soothill and Steward, 1971), a factor at least partly under genetic control. It has always been difficult to explain the extreme rarity of subacute sclerosing panencephalitis if it is really due to the almost ubiquitous measles virus. If immune complexes are important in its pathogenesis, however, then perhaps only those rare individuals who make low affinity antibody are in danger of developing this disease; and only then, perhaps, if virus lodges in the thymus (Burnet, 1968) or if simultaneous infection with another virus (Dayan, 1971; Koprowski et al., 1970) occurs at a critical stage in the evolution of the disease.

We are grateful to Dr. M. J. McArdle for permission to study this patient, Dr. J. A. Dudgeon for estimating the measles antibodies, Professor K. A. Porter for advice, and Drs. A. N. Bowden and J. A. Rees for their help. We wish to thank the Peel Trust and the Cancer Research Campaign for their support.

\section{References}

Burnet, M. (1968). Lancet, 2, 610.

Cochrane, C. G. (1971). Fournal of Experimental Medicine, 134, 75s.

Connolly, J. H., Allen, I. V., Hurwitz, L. J., and Millar, J. H. D. (1968). Quarterly fournal of Medicine, 37, 625 .

Dandliker, W. B., et al. (1967). Biochemistry, 6, 1460.

Dayan, A. D. (1971). Fournal of the Neurological Sciences, 14, 315.

Freedman, P., and Markowitz, A. S. (1962). British Medical fournal, 1, 1175.

Henson, P. M. (1971). Fournal of Experimental Medicine, 134, 115s.

Horta-Barbosa, L., Fuccillo, D., Sever, J. L., Zeman, W., and Mealey, J. (1969). Nature, 221, 974 .

Horta-Barbosa, L., et al. (1971). Science, 173, 840.

Houba, V., et al. (1970). In Immune Complex Diseases, ed. L. Bonomo and J. L. Turk, p. 23. Milan, Carlo Erba Foundation.

Koprowski, H., Barbanti-Brodano, G., and Katz, M. (1970). Nature,

ter Meulen, V., Enders-Ruckle, G., Müller, D., and Joppich, G. (1969). Acta Neuropathologica, 12, 244.

Notkins, A. L. (1971). Fournal of Experimental Medicine, 134, 41s.

Notkins, A. L. (1971). Fournal of Experimental Medicine, 134, 41s.
Oldstone, M. B. A., and Dixon, F. J. (1969). Fournal of Experimental Medicine, $129,483$.

Oldstone, M. B. A., and Dixon, F. J. (1971). Fournal of Experimental Medicine, $134,32 \mathrm{~s}$.

Payne, F. E., Baublis, J. V., and Itabashi, H. H. (1969). New England fournal of Medicine, $281,585$. Sever, J. L., and Zeman, W. (1968). Neurology (Minneapolis), 18, Suppl. Soothill, J. F., and Steward, M. W. (1971). Clinical and Experimental

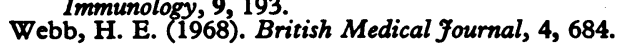

\title{
Pancreatin as a Source of Hospital-acquired Salmonellosis
}

\author{
E. J. G. GLENCROSS
}

British Medical fournal, 1972, 2, 376-378

\section{Introduction}

Summary

Two babies with fibrocystic disease of the pancreas acquired hospital infection with Salmonella agona after treatment with commercial pancreatin prepared from pig pancreas obtained from abattoirs in Britain.

The incidence of salmonellosis in apparently healthy pigs slaughtered in this country will obviously vary from time to time and place to place, but is known to increase if animals are herded together just before slaughter (McDonagh and Smith, 1958). In the symptomless carrier state in pigs salmonellae are probably restricted to the bowel and mesenteric lymph nodes (Smith, 1960), but spread to other parts of the carcass is likely during evisceration (Galton et al., 1954). Sick animals suffering from salmonella septicaemia, with consequent widespread dissemination of organisms throughout the animal, are, however, unlikely to be accepted by the abattoir. 
Thus pancreatin, prepared from pig pancreas collected at abattoirs, may be contaminated with salmonellae, and physical methods certain to render the final product safe are difficult to apply because of adverse effects on enzyme activity.

Thyroid also prepared from animal tissue has already been responsible for an outbreak of Salmonella muenchen and $S$. bareilly infection in Sweden (Kallings et al., 1966), but no salmonellae were found in an extensive range of drugs for oral and topical use, including thyroid tablets, in an investigation by the Pharmaceutical Society of Great Britain (1971).

Recorded here is an incident of $S$. agona infection in two children in hospital with malabsorption syndrome who were treated with pancreatin found subsequently to be contaminated with salmonellae.

\section{Clinical Records}

The first infection involved a 4-month-old baby admitted to hospital on 10 November 1971 for investigation of a feeding problem. Two faecal specimens collected on 12 and 13 November, and examined as a routine admission procedure, were found to be free of bacterial pathogens. Subsequently, biochemical tests and the appearance of the stool suggested a malabsorption syndrome, and because this was thought to be associated with fibrocystic disease of the pancreas a therapeutic trial with oral pancreatin and cloxacillin began on 19 November. Two days later the baby became pyrexial, and this was thought to be the result of upper respiratory tract infection, but examination of a stool specimen taken on 21 November yielded $S$. agona. At no time did this baby develop gastroenteritis, and as his temperature settled rapidly he was discharged home on 22 November, where he continued to excrete $S$. agona for at least six weeks after discharge. A single specimen of faeces from each parent was examined for $S$. agona with negative result.

As this baby was considered to have been infected in hospital, faecal specimens from all ward contacts, both staff and patients, were collected and examined for $S$. agona. This investigation resulted in the discovery of a second excreter of $S$. agona, a 5-month-old patient, on 25 November. This second child had been in the same ward for five days for treatment of a respiratory tract infection associated with fibrocystic disease of the pancreas, and had almost certainly received the same batch of pancreatin as the first baby. This second excreter had initially no gastrointestinal symptoms, but after discharge home on 27 November he developed loose blood-flecked motions and was readmitted one week later. S. agona was reisolated from the stool, as it was also from six out of six household contacts.

The pancreatin thus came under strong suspicion as being the common vehicle of infection for both children and was investigated accordingly.

\section{Bacteriological Investigation of Pancreatin}

Method.-The pancreatin powder was suspended and shaken with 10 times its weight of sterile water in a screw-capped jar, and an equal volume of double-strength selenite broth (Oxoid CM39) added one to two hours later. After incubation for 24 hours at $37^{\circ} \mathrm{C}$ subcultures were made to desoxycholate citrate agar (Oxoid CM35). After overnight incubation suspect nonlactose-fermenting colonies were identified as salmonellae by standard serological and biochemical techniques. Final identification of the serotypes was undertaken by the Salmonella Reference Laboratory, Central Public Health Laboratory, Colindale, London.

Results.-No salmonellae were isolated from $0.5 \mathrm{~g}$ of the suspect pancreatin, but examination of $10 \mathrm{~g}$ yielded three serotypes-namely, $S$. agona, $S$. brandenburg, and $S$. anatum. From $10 \mathrm{~g}$ of each of three identical, but unopened bottles, held as pharmacy stock, isolates of $S$. agona; S. brandenburg; and
$S$. agona, $S$. brandenburg, and $S$. infantis were made respectively. No salmonellae were isolated from two different batches of pancreatin produced by the same manufacturers, nor from faecal specimens obtained from the pharmacy staff.

\section{Discussion}

Pancreatin has been shown to be the source of $S$. agona infection in two babies in hospital, one becoming a symptomless excreter and the other eventually developing a mild gastroenteritis which necessitated readmission to hospital. Infection spread throughout the six household contacts of the baby who developed symptoms, and although it was difficult to obtain an accurate retrospective history of illness in these contacts, none sought treatment from their family doctor.

Manufacturers who process animal tissues into active enzyme preparations are aware of the risk of salmonellae contaminating their final product, and the manufacturer who processed the pancreatin involved in this incident of hospital infection routinely adopts certain precautions with this risk in mind, and I am grateful to the firm for supplying the following details.

The raw material, pig pancreas collected from abattoirs by a commercial gland supplier, is kept deep frozen until just before use, when it is allowed to thaw in lots of $140 \mathrm{~kg}$. Sufficient Chloros is added in 10 litres of water to give a final concentration of $0.2 \%$ in a total mix of $150 \mathrm{~kg}$. This mix is then minced, sieved, and allowed to stand for 45 minutes before vacuum drying at a controlled temperature for several hours. The manufacturers confirm that this treatment with hypochlorite, introduced since the contaminated batch was processed, has reduced the number of batches of pancreatin subsequently found to contain salmonellae. After vacuum drying the powder is fat extracted, gently redried to remove the solvent, and then mill-ground to give a final yield of between 10 and $20 \mathrm{~kg}$ of a very fine slightly buff coloured powder. This powder is then set aside in bulk in a cool store, away from possible recontamination from raw materials, until two $25-\mathrm{g}$ samples are declared free from salmonellae by an independent bacteriologist. The risk of contamination passing from batch to batch during processing is recognized, and reduced by the routine stripping, cleaning, and disinfection of equipment with hypochlorite solution.

However, despite these precautions a batch of contaminated pancreatin was released by the firm to hospital and retail pharmacies during October 1971. Unused stock was withdrawn by the manufacturer in early December, soon after notification of the incident of infection described in this paper.

It is generally considered that the dose of salmonellae required to produce symptoms of gastroenteritis is high and usually in the order of several million bacteria, although considerable variation may occur with the strain and susceptibility of the patient (McCullough and Eisele, 1951a, 1951b). In salmonella food poisoning the high infecting dose follows environmental conditions that allow for bacterial multiplication before the ingestion of the contaminated food. No such multiplication was possible here as the pancreatin was added to a little milk or cereal just before each feed, and the failure to isolate salmonellae from $0.5 \mathrm{~g}$ of contaminated pancreatin, which was twice the dose given to the babies at each feed, indicates that the total infection dose was small over the few days that each baby received treatment. However, from studies of the spread of salmonellae in hospital wards "small dose" infection is believed to occur, and it is possible that the intestine of babies with a malabsorption syndrome is more easily colonized than that of healthy children or adults. Of the serotypes present in the pancreatin only $S$. agona was apparently capable of such "small dose" infection.

At present there are no microbiological standards for pancreatin in the current edition of the British Pharmacopoeia, but such proposals, which include the absence of salmonellae from a given weight of powder, are under consideration by the British Pharmacopoeia Commission. 
I am grateful to Dr. B. W. Powell, consultant paediatrician, for providing access to the clinical records of both babies.

\section{References}

Galton, M. M., Smith, W. V., McElrath, H. B., and Hardy, A. V. (1954). fournal of Infectious Diseases, 95, 236.
Kallings, L. O., Ringertz, O., and Silverstolpe, L. (1966). Acta Pharmaceutica Suecica, 3, 219.

McCullough, N. B., and Eisle, C. W. (1951a). Fournal of Infectious Diseases, 88, 278.

McCullough, N. B., and Eisele, C. W. (1951b). Fournal of Infectious Diseases, $89,209,259$.

McDonagh, V. P., and Smith, H. G. (1958). Fournal of Hygeine, 56, 271.

Pharmaceutical Society (1971). Pharmaceutical fournal, 207, 400.

Smith, H. W. (1960). Fournal of Hygiene, 58, 381 .

\section{Short-term Evaluation of Synovectomy in Haemophilia}

\section{PIETROGRANDE， N. DIOGUARDI， P. M. MANNUCCI}

British Medical fournal, 1972, 2, 378-381

\begin{abstract}
Summary
Twenty-three operations of synovectomy (15 on the knee, 5 on the ankle, and 3 on the elbow) were carried out over a three-year period in 19 patients with severe haemophilia $A$ and $B$ who were followed for an average period of 15 months postoperatively. Short-term evaluation of the results was mainly based on the postoperative incidence of haemarthrosis and on the range of joint motion, which were compared with the preoperative findings. Synovectomy reduced, but did not abolish, the occurrence of haemarthrosis; however, after the operation bleeding episodes were usually less severe and incapacitating. Joint mobility was often reduced despite an intensive and prolonged programme of physiotherapy. Nevertheless, most of the patients were pleased with the results of the operation as they could lead a more active life because of the decreased risk of joint bleeding.

In the light of these findings we conclude that synovectomy is not the elective treatment of choice for haemophilic arthropathy. It may be indicated in a few selected cases when conservative treatment has failed to control repeated haemarthrosis and synovitis. Controlled clinical trials and long-term evaluation are needed to establish its effect on the final outcome of haemophilic arthropathy.
\end{abstract}

\section{Introduction}

The risk of haemorrhage associated with any surgical procedure has severely limited orthopaedic surgery in haemophiliacs. This is reflected in the relatively small number of orthopaedic operations carried out in the past 20 years and in the fact that most reported cases were emergencies, such as amputations and reductions of fractures. General reviews of this problem, with description of extensive personal experience, have been published by Ahlberg (1965) and Trueta (1966).

The recent increased availability of new and more potent concentrates of clotting factors, together with more favourable results with general surgical procedures, should change the pattern of orthopaedic surgery in these patients. Elective surgery, which can now be undertaken in specialized units without undue risk, offers a means of correcting established deformities and reducing disability. Moreover, synovectomy has been proposed for the prevention of arthropathy on the basis

Isntituto G. Pini, University of Milan, Italy

V. PIETROGRANDE, M.D., Professor of Orthopaedic Surgery

Institute of Medical Pathology, University of Milan, Italy

N. DIOGUARDI, M.D., Professor of Medicine

P. M. MANNUCCI, M.D., Senior Lecturer in Medicine and Physician, Haemophilia Centre of excellent results characterized by the absence of new episodes of haemarthrosis and by pronounced functional improvement in the joint (Storti et al., 1969). A consistent amelioration of the general bleeding tendency was also found, as expressed by the decrease in number and severity of the bleeding episodes in sites other than in the operated joints (Storti et al., 1969).

This paper evaluates the results of a programme for the elective surgical management of haemophilic arthropathy based on synovectomy. The purpose of the study was to observe and document the short-term effect of the operation on the occurrence of haemarthrosis and on the range of joint movement in 19 patients who were followed for an average of 15 months postoperatively.

\section{Material and Methods}

Twenty-three synovectomies (15 on the knee, 5 on the ankle, and 3 on the elbow) were carried out over a three-year period in 19 patients with severe haemophilia A or B (factor VIII or IX less than $2 \%$ ). On several occasions more than one procedure was performed at one time to take full advantage of the protection given by the replacement therapy. The patients' ages at the time of surgery ranged from 4 to 51 years (see Table).

Of the 19 patients 13 had been regularly followed at the haemophilia centre and at the orthopaedic clinic for at least 12 months before the operation, and their bleeding episodes and substitution therapy had been recorded. The remaining patients were referred from other hospitals, and hence their preoperative records were not available.

Synovectomy was the procedure of choice in patients presenting with a persistent tendency to recurrent haemorrhages in the same joint (knee, elbow, and ankle) and with local signs of synovitis (swelling, heat, and thickening of the periarticular tissues). Other criteria of selection were the absence of severe radiological changes and good preservation of joint mobility corresponding largely to grades 1 and 2 of the classification of haemophilic arthropathy proposed by De Palma and Cotler (1956). The age of the patients did not affect their selection for synovectomy. The indication for operation was established after conservative treatment (early substitution therapy or short courses of regular prophylaxis with concentrates associated with corticosteroids given either locally or parenterally) had failed to produce a consistent improvement.

Surgical Technique.-The objective of synovectomy was to remove as much as possible of the synovial membrane without interfering with the function and stability of the ligament mechanism. The knee was approached through two parapatellar incisions, the elbow with a single lateral incision, and the ankle with two incisions, one medial and the other lateral. Aprotinin (Trasylol) was injected into the joints at the end of the operation (200,000-300,000 IU).

Postoperative Treatment and Follow-up.-After wound closure the knee and ankle were immobilized with a well-padded plaster cast for 15 days. Crutch walking with a posterior splint was 